\title{
When a Burr Can Not Penetrate the Calcified Lesion, Increasing Burr Size as Well as Decreasing Burr Size Can Be a Solution in Rotational Atherectomy
}

\author{
Kenichi SaKakura, ${ }^{1}$ MD, Yousuke Taniguchi, ${ }^{1}$ MD, Kei Yamamoto, ${ }^{1}$ MD, \\ Hiroshi Wada, ${ }^{1} \mathrm{MD}$, Shin-ichi Momomura, ${ }^{1} \mathrm{MD}$, and Hideo Fujita, ${ }^{1} \mathrm{MD}$
}

\begin{abstract}
SUMMARY
In rotational atherectomy (RA), several burr sizes are available, such as $1.25 \mathrm{~mm}, 1.5 \mathrm{~mm}, 1.75 \mathrm{~mm}$, or $\geq 2.0 \mathrm{~mm}$. It is important to select an appropriate burr size for each lesion because rotational atherectomy has several unique complications regarding burrs such as entrapment or perforation. When a burr cannot penetrate the lesion, downsizing of the burr is generally recommended. Also, if the smallest burr $(1.25 \mathrm{~mm})$ cannot penetrate the lesion, a change to a more supportive or larger French guiding catheter has been recommended. We describe the case of a 68 year-old female who was referred to our department for percutaneous coronary intervention to the calcified stenosis in the middle of the left anterior descending coronary artery. We used the smallest burr $(1.25 \mathrm{~mm})$ and a supportive $7 \mathrm{Fr}$ guiding catheter to penetrate the lesion. However, the smallest burr could not pass the lesion even after 14 sessions (total ablation time: 339 seconds). We intentionally increased the burr size from $1.25 \mathrm{~mm}$ to $1.5 \mathrm{~mm}$. The $1.5 \mathrm{~mm}$ burr successfully passed the lesion without any perforation or burr entrapment. In this manuscript, we discuss why increasing the burr size was successful for this severely calcified lesion that was not penetrated by the smallest burr. (Int Heart J 2017; 58: 279-282)
\end{abstract}

Key words: Percutaneous coronary intervention

$\mathrm{R}$ otational atherectomy (RA) remains an essential procedure for severely calcified lesions in current percutaneous coronary intervention (PCI). ${ }^{1,2)}$ While there are several burr sizes such as $1.25 \mathrm{~mm}, 1.5 \mathrm{~mm}, 1.75 \mathrm{~mm}$, and $\geq$ $2.0 \mathrm{~mm}$, it is important to select the appropriate burr size for each lesion because RA has several unique complications regarding burrs such as entrapment or perforation. ${ }^{3-5)}$ Small burrs $(1.25 \mathrm{~mm}$ or $1.5 \mathrm{~mm})$ are more preferable than large burrs $(1.75 \mathrm{~mm}$ or $2.0 \mathrm{~mm})$ in current $\mathrm{PCI}^{1,6)}$ because the indication for RA is mostly lesion modification followed by drug-eluting stent (DES) implantation. Also, when a burr cannot penetrate the lesion, downsizing of the burr is generally recommended. ${ }^{6}$ If the smallest burr $(1.25 \mathrm{~mm})$ cannot penetrate the lesion, a change to a more supportive or larger French guiding catheter has been recommended. ${ }^{6}$

We present here a case with a severely calcified lesion, which was treated by RA. We used the smallest burr $(1.25$ $\mathrm{mm}$ ) and a supportive 7 Fr guiding catheter to penetrate the lesion. However, the smallest burr could not pass the lesion. We intentionally increased the burr size from $1.25 \mathrm{~mm}$ to $1.5 \mathrm{~mm}$. The $1.5 \mathrm{~mm}$ burr passed through the lesion that could not be penetrated by the $1.25 \mathrm{~mm}$ burr without burr entrapment or perforation.

\section{Case Report}

A 68-year-old female with stable angina pectoris was referred to our department for PCI to a calcified stenosis in the middle of the left anterior descending (LAD) coronary artery. A 7-Fr CLS 3.5 SH guide catheter (Boston Scientific, Natrick, MA, USA) was inserted into the left coronary artery via the right brachial artery (Figure 1A). Quantitative coronary analysis revealed that the lesion length and reference diameter were $23.4 \mathrm{~mm}$ and $2.1 \mathrm{~mm}$, respectively. We advanced a conventional 0.014 inch guide wire beyond the lesion, and attempted to advance an intravascular ultrasound (IVUS) catheter (Navifocus WR, Terumo, Tokyo). However, the IVUS catheter could not pass the lesion. Therefore, we decided to perform RA. We exchanged the conventional guide wire for a rotawire floppy (Boston Scientific). We advanced the $1.25 \mathrm{~mm}$ burr (burr-toartery ratio $=0.60)(190,000 \mathrm{rpm})$ to the lesion, but the 1.25 $\mathrm{mm}$ burr could not pass the lesion even after 6 sessions (total ablation time: 146 seconds). We exchanged the rotawire floppy for the rotawire extra-support (Boston Scientific), but the 1.25 $\mathrm{mm}$ burr could not pass the lesion even after 8 sessions (total ablation time: 193 seconds) (Figure 1B). We exchanged the $1.25 \mathrm{~mm}$ burr for a $1.5 \mathrm{~mm}$ burr (burr-to-artery ratio $=0.71$ ), and the $1.5 \mathrm{~mm}$ burr could pass the lesion (total ablation time: 84 seconds) (Figure 1C). The details of the ablation time and

From the ${ }^{1}$ Division of Cardiovascular Medicine, Saitama Medical Center, Jichi Medical University, Saitama, Japan.

Address for correspondence: Kenichi Sakakura, MD, Division of Cardiovascular Medicine, Saitama Medical Center, Jichi Medical University, 1-847 Amanuma, Omiya-ku, Saitama, Saitama 330-8503 Japan. E-mail: ksakakura@jichi.ac.jp

Received for publication May 23, 2016. Revised and accepted July 26, 2016

Released in advance online on J-STAGE March 2, 2017.

All rights reserved by the International Heart Journal Association. 


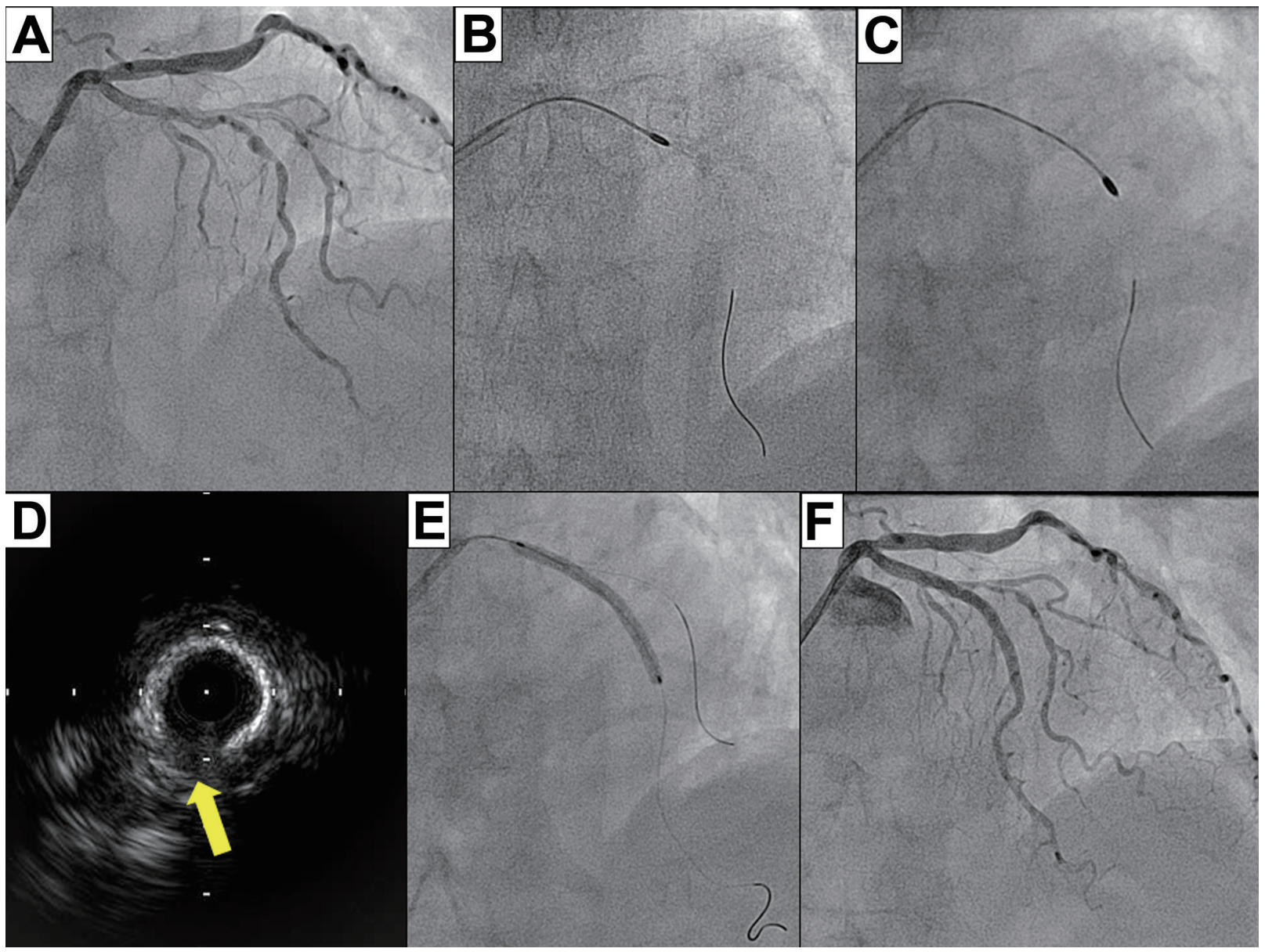

Figure 1. A: Coronary angiography shows calcified stenosis in the middle of the left anterior descending artery (LAD). B: The $1.25 \mathrm{~mm}$ burr could not penetrate the calcified lesion. C: The $1.5 \mathrm{~mm}$ burr could pass through the calcified lesion. D: Intravascular ultrasound shows circumferential calcification with a crack (arrow). E: An everolimus-eluting stent $(2.5 \times 38 \mathrm{~mm})$ was deployed. F: Final angiogram.

Table. Ablation Time and Rotation Speed During Rotational Atherectomy

\begin{tabular}{|c|c|c|c|c|c|c|c|c|c|}
\hline \multirow{2}{*}{$\begin{array}{l}\text { Number of } \\
\text { sessions }\end{array}$} & \multicolumn{3}{|c|}{$\begin{array}{l}\text { Burr } 1.25 \mathrm{~mm} \\
\text { using rotawire floppy }\end{array}$} & \multicolumn{3}{|c|}{$\begin{array}{c}\text { Burr } 1.25 \mathrm{~mm} \\
\text { using rotawire extra-support }\end{array}$} & \multicolumn{3}{|c|}{$\begin{array}{l}\text { Burr } 1.5 \mathrm{~mm} \\
\text { using rotawire extra-support }\end{array}$} \\
\hline & $\begin{array}{l}\text { Rotational } \\
\text { speed } \\
(\mathrm{rpm})\end{array}$ & $\begin{array}{l}\text { Ablation } \\
\text { time } \\
\text { (seconds) }\end{array}$ & $\begin{array}{c}\text { Maximum } \\
\text { speed reduction } \\
(\mathrm{rpm})\end{array}$ & $\begin{array}{l}\text { Rotational } \\
\text { speed } \\
\text { (rpm) }\end{array}$ & $\begin{array}{l}\text { Ablation } \\
\text { time } \\
\text { (seconds) }\end{array}$ & $\begin{array}{c}\text { Maximum } \\
\text { speed reduction } \\
(\mathrm{rpm})\end{array}$ & $\begin{array}{l}\text { Rotational } \\
\text { speed } \\
(\mathrm{rpm})\end{array}$ & $\begin{array}{l}\text { Ablation } \\
\text { time } \\
\text { (seconds) }\end{array}$ & $\begin{array}{c}\text { Maximum } \\
\text { speed reduction } \\
(\mathrm{rpm})\end{array}$ \\
\hline 1 & 187,000 & 15 & $-6,000$ & 187,000 & 23 & $-6,000$ & 194,000 & 21 & $-2,000$ \\
\hline 2 & 183,000 & 21 & $-2,000$ & 181,000 & 25 & $-3,000$ & 193,000 & 16 & $-3,000$ \\
\hline 3 & 179,000 & 27 & $-1,000$ & 178,000 & 25 & $-2,000$ & 189,000 & 17 & $-2,000$ \\
\hline 4 & 176,000 & 30 & $-2,000$ & 176,000 & 29 & $-2,000$ & 187,000 & 18 & $-1,000$ \\
\hline 5 & 175,000 & 29 & $-2,000$ & 175,000 & 29 & $-2,000$ & 187,000 & 6 & $-2,000$ \\
\hline 6 & 174,000 & 24 & $-2,000$ & 192,000 & 30 & $-1,000$ & 189,000 & 6 & $-2,000$ \\
\hline 7 & & & & 193,000 & 25 & $-1,000$ & & & \\
\hline 8 & & & & 190,000 & 7 & $-1,000$ & & & \\
\hline
\end{tabular}

rotation speed in each session are shown in the Table. The IVUS catheter could easily pass the lesion, and showed circumferential calcification with a crack (Figure 1D). Following balloon dilatation, we deployed an everolimus-eluting stent $(2.5 \times 38 \mathrm{~mm})$ (Figure 1E), and achieved TIMI-3 grade flow (Figure 1F).

\section{Discussion}

Decreasing the burr size is the standard procedure when the burr cannot penetrate the lesion. ${ }^{6}$ However, if the smallest burr $(1.25 \mathrm{~mm})$ could not pass the lesion, there are a few options. Changing the guide wire from rotawire floppy to rotawire extra-support (or from extra-support to floppy) is one option, but it did not work in our case. Increasing the burr size 
was effective in our case, but we should be cautious about performing this procedure because increasing the burr size may worsen the situation. We should speculate on the mechanism as to why increasing the burr size worked for the calcified lesion that was not penetrated by the smallest burr. Before dis-

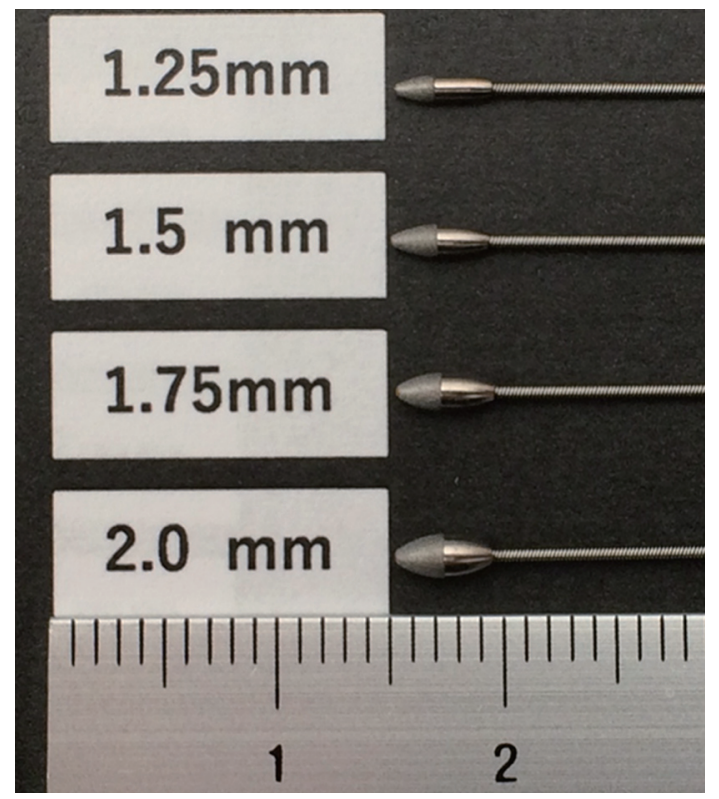

Figure 2. Shape and size of each burr. cussing the mechanism, we need to know the size and shape of RA burrs $(1.25 \mathrm{~mm}, 1.5 \mathrm{~mm}, 1.75 \mathrm{~mm}$, and $2.0 \mathrm{~mm}$ ) (Figure 2 ). The shape of each burr is close to ellipsoid. While the short axes are different between the burrs, the long axes are approximately the same between the burrs (Figure 2 and Figure 3). Therefore, the required vessel diameters for $1.25 \mathrm{~mm}, 1.5 \mathrm{~mm}$, $1.75 \mathrm{~mm}$, and $2.0 \mathrm{~mm}$ burrs in horizontal positions are 1.25 $\mathrm{mm}, 1.5 \mathrm{~mm}, 1.75 \mathrm{~mm}$, and $2.0 \mathrm{~mm}$, respectively (Figure 3A, B). However, vessel diameters required for burrs in an oblique position are different from those for burrs in a horizontal position. Because the sizes of the long axis are the same between the burrs, the vessel diameters required in oblique burrs are similar between the burrs (Figure 3C, D).

We introduced a simplified model to clarify why the 1.5 $\mathrm{mm}$ burr penetrated the lesion that was not penetrated by the $1.25 \mathrm{~mm}$ burr (Figure 4). The $1.25 \mathrm{~mm}$ burr can advance the straight part of the calcified vessel, because the burr size (1.25 $\mathrm{mm})$ is identical to the lumen diameter $(1.25 \mathrm{~mm})$ (Figure 4A). However, the $1.25 \mathrm{~mm}$ burr cannot advance the angled part of the calcified vessel because the lumen diameter $(1.25 \mathrm{~mm})$ is not large enough for an oblique $1.25 \mathrm{~mm}$ burr (Figure 4B). On the other hand, the $1.5 \mathrm{~mm}$ burr could be advanced the straight part of the calcified vessel with dilation of the calcified lumen (from $1.25 \mathrm{~mm}$ to $1.5 \mathrm{~mm}$ ) (Figure 4C). The $1.5 \mathrm{~mm}$ burr could be advanced the angled part of the calcified vessel because the lumen diameter $(1.5 \mathrm{~mm})$ was large enough for an oblique $1.5 \mathrm{~mm}$ burr (Figure 4D). This phenomenon can occur because the required vessel diameter for the oblique $1.25 \mathrm{~mm}$ burr is very similar to that for the oblique $1.5 \mathrm{~mm}$ burr, while

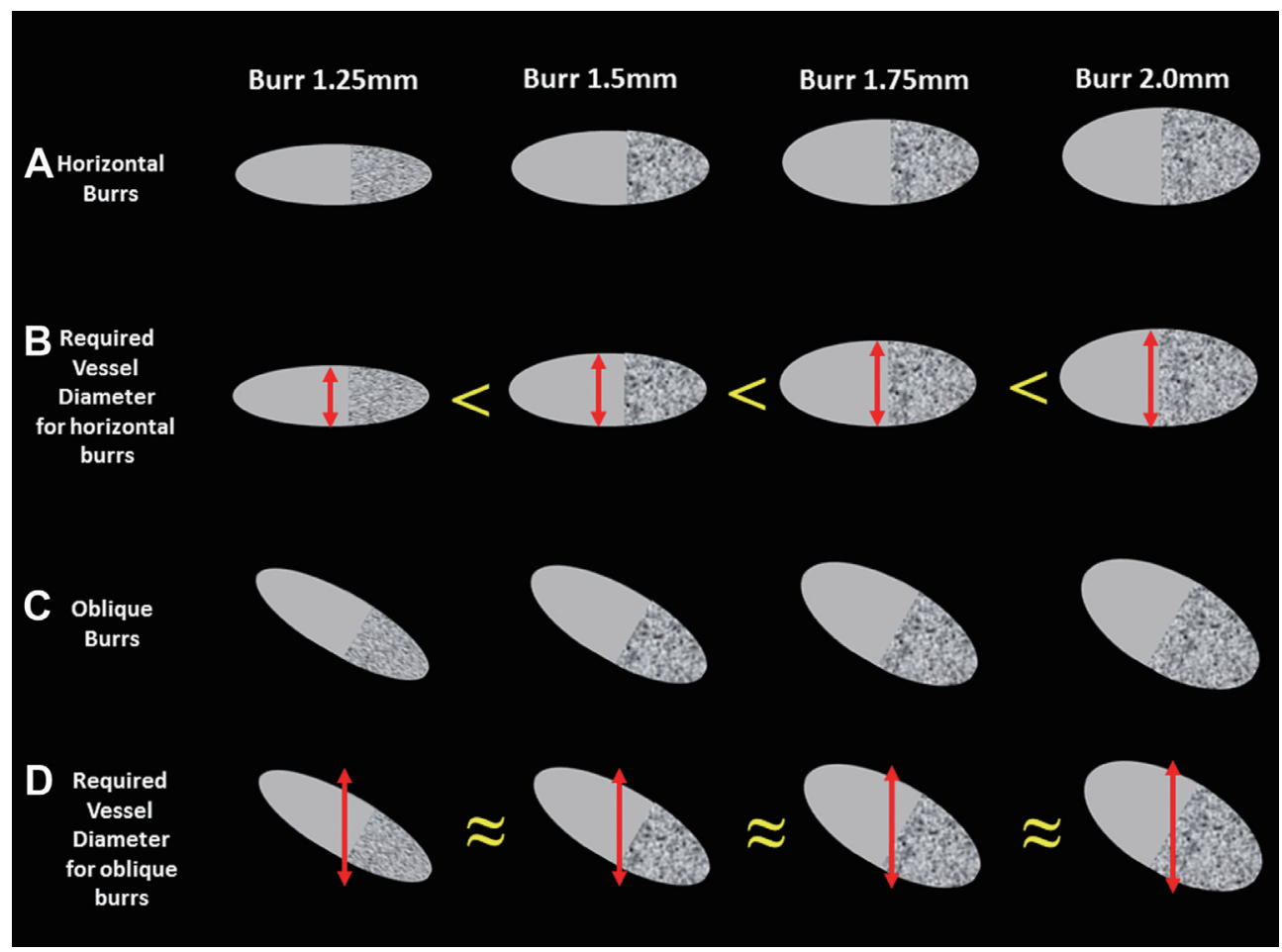

Figure 3. Horizontal burrs and oblique burrs. A: While the sizes of the short axes are different between the burrs, the sizes of the long axes are the same between the burrs. B: The required vessel diameters for horizontal $1.25 \mathrm{~mm}, 1.5 \mathrm{~mm}, 1.75$ $\mathrm{mm}$, and $2.0 \mathrm{~mm}$ burrs are $1.25 \mathrm{~mm}, 1.5 \mathrm{~mm}, 1.75 \mathrm{~mm}$, and $2.0 \mathrm{~mm}$, respectively. C: Oblique burrs. D: Required vessel diameters for oblique burrs are different from those for horizontal burrs. Because the sizes of the long axes are the same between the burrs, the required vessel diameters in oblique burrs are similar between the burrs. 


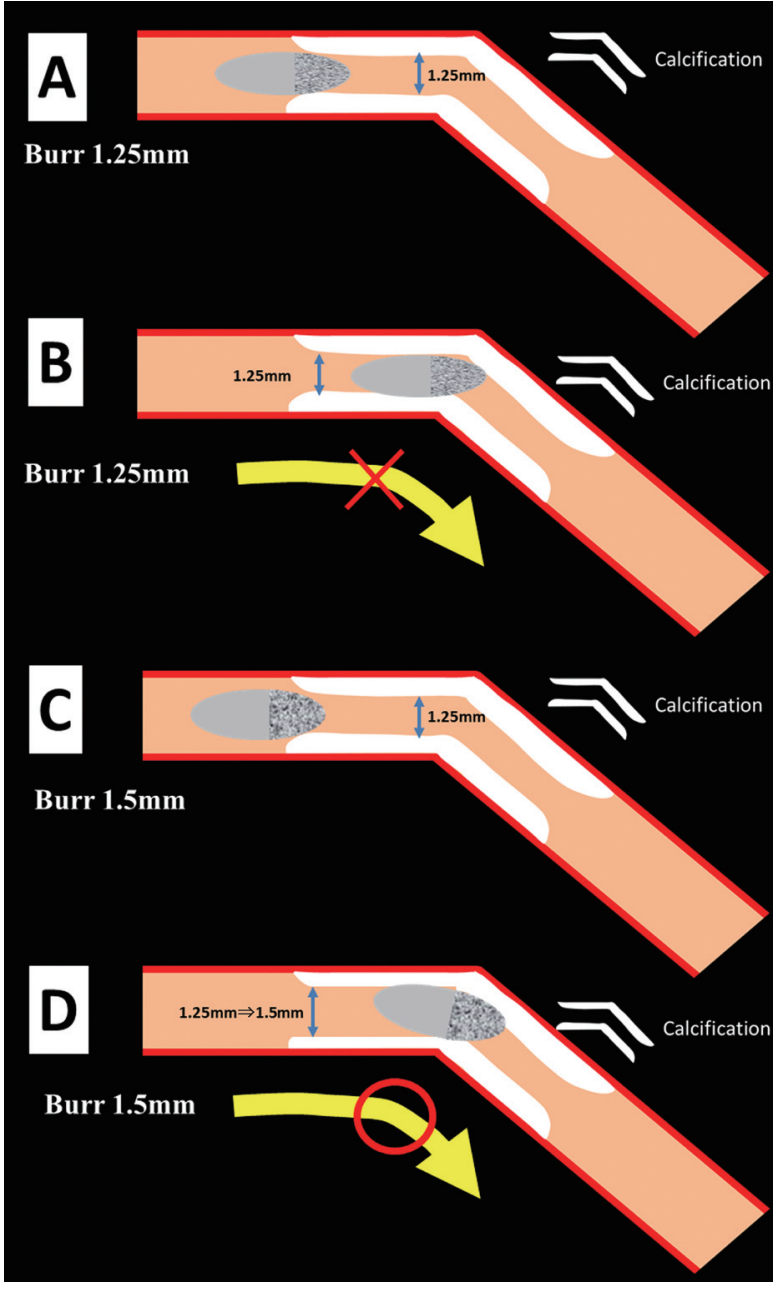

Figure 4. Scheme to clarify why the $1.5 \mathrm{~mm}$ burr penetrated the lesion that was not penetrated by the $1.25 \mathrm{~mm}$ burr. A: The $1.25 \mathrm{~mm}$ burr could be advanced to the straight part of the calcified vessel because the burr size $(1.25 \mathrm{~mm})$ was identical to the lumen diameter $(1.25 \mathrm{~mm})$. B: The 1.25 $\mathrm{mm}$ burr could not be advanced to the angled part of the calcified vessel because the lumen diameter $(1.25 \mathrm{~mm})$ was not large enough for an oblique $1.25 \mathrm{~mm}$ burr. C: On the other hand, the $1.5 \mathrm{~mm}$ burr could be advanced to the straight part of the calcified vessel with dilation of the calcified lumen (from $1.25 \mathrm{~mm}$ to $1.5 \mathrm{~mm}$ ). D: The $1.5 \mathrm{~mm}$ burr could be advanced to the angled part of the calcified vessel because the lumen diameter $(1.5 \mathrm{~mm})$ was large enough for an oblique $1.5 \mathrm{~mm}$ burr.

the $1.5 \mathrm{~mm}$ burr can ablate much more calcification than the $1.25 \mathrm{~mm}$ burr.

Since increasing burr size is not a standard procedure when the burr cannot penetrate the lesion, we should check rotational speed reduction before increasing burr size. It is important not to increase the burr size when there is substantial rotational speed reduction, because substantial rotational speed reduction means that the burr is ablating coronary plaques with or without calcification. In our case, there was little rotational speed reduction in the last 3 sessions using the $1.25 \mathrm{~mm}$ burr, which means that the burr hardly ablated any plaques in the last 3 sessions. Changing the guide wire from rotawire floppy to rotawire extra-support can be attempted before increasing the burr size, because changing guide wires may be an easier and safer approach than increasing burr size. Furthermore, we should not fixate on penetration of the burr, especially when there is a steep angle within the lesion. We can switch the RA to balloon dilatation, when the burr ablated calcified plaques just before the steep angle (halfway rotational atherectomy). ${ }^{7}$ Halfway rotational atherectomy, which means that an operator does not advance the burr beyond the steep angle, would be a safer approach to avoid fatal complications in an angulated calcified lesion. ${ }^{7}$ We should mention the limitations of our hypothesis. We do not have information regarding the exact size and shape of each burr, because the official design of each burr was not available to us. The sizes of the long axis of each burr may not be the same, but are at least similar. While we approximated the shape of each burr as ellipsoid, it may not be ellipsoid, especially the smallest burr $(1.25 \mathrm{~mm})$. The shape of the smallest burr might have made it prone to become entrapped in the calcified lesion. Furthermore, atherosclerosis in human coronary arteries is more complex than the model that we introduced. Therefore, there might be other reasons to explain why the large burr could pass through a lesion that the small burr could not.

In conclusion, increasing the burr size as well as decreasing the burr size can be an option when the burr cannot penetrate the lesion. It is important for interventional cardiologists to consider the reason why a burr cannot advance through a lesion because interventional cardiologists need to select the most appropriate way from several options such as changing the burr size, changing the guidewire, changing the rotational speed, and even terminating the RA.

\section{Disclosures}

Dr. Sakakura has received speaking honoraria from Abbott Vascular, Boston Scientific, Medtronic Cardiovascular, and Terumo; and has served as a consultant for both Abbott Vascular and Boston Scientific.

\section{REFERENCES}

1. Tomey MI, Kini AS, Sharma SK. Current status of rotational atherectomy. JACC Cardiovasc Interv 2014; 7: 345-53. (Review)

2. Tamura H, Miyauchi K, Dohi T, et al. Comparison of clinical and angiographic outcomes after bare metal stents and drug-eluting stents following rotational atherectomy. Int Heart J 2016; 57: 1507.

3. Yamamoto S, Sakakura K, Funayama H, Wada H, Fujita H, Momomura S. Percutaneous coronary artery bypass for type 3 coronary perforation. JACC Cardiovasc Interv 2015; 8: 1396-8.

4. Sakakura K, Ako J, Wada H, et al. Comparison of frequency of complications with on-label versus off-label use of rotational atherectomy. Am J Cardiol 2012; 110: 498-501.

5. Sakakura K, Ako J, Momomura S. Successful removal of an entrapped rotablation burr by extracting drive shaft sheath followed by balloon dilatation. Catheter Cardiovasc Interv 2011; 78: 56770.

6. Barbato E, Carrié D, Dardas P, et al. European expert consensus on rotational atherectomy. EuroIntervention 2015; 11: 30-6.

7. Sakakura K, Taniguchi Y, Matsumoto M, Wada H, Momomura S, Fujita H. How should we perform rotational atherectomy to an angulated calcified lesion? Int Heart J 2016; 57: 376-9. 